\title{
CUTANEOUS MANIFESTATIONS OF POLYCYSTIC OVARIAN DISEASE
}

\author{
Thakur Rajeev Singh ${ }^{1}$, Sathaiah Sudhamalla ${ }^{2}$
}

${ }_{1}^{1}$ Associate Professor, Department of DVL, Gandhi Medical College, Secunderabad, Telangana, India.

${ }^{2}$ Senior Resident, Department of DVL, Gandhi Medical College, Secunderabad, Telangana, India.

\section{BACKGROUND}

\section{ABSTRACT}

Polycystic ovarian disease (PCOD) is an ill-defined heterogeneous condition with a complex pathophysiology and is one of the commonest endocrine/metabolic disorders, affecting $6-10 \%$ of women in their reproductive age. Polycystic ovarian disease is the most common endocrine cause of hirsutism, acne and androgenic alopecia.

\section{MATERIALS AND METHODS}

Informed oral consent was obtained from all subjects after explanation of the nature and purpose of the study. A special case proforma was prepared to record the demographic data, complaints, history, clinical examination and results of investigations. A detailed history regarding menstrual irregularities, reproductive function, hirsutism, acne, androgenic alopecia, acanthosis nigricans, acrochordons, seborrhoea and other skin changes. Patients were also enquired about use of cosmetics, hoarseness of voice, headache, milky discharge from breast, mass over anterior neck, weight gain, diet, exercise, use of any medications or other forms of treatment, any stress/illness, history of diabetes mellitus, hypertension and coronary artery disease. Family history of polycystic ovarian disease, diabetes mellitus, hypertension, coronary artery disease, metabolic syndrome and cancers was also taken. Menstrual and obstetric history and any medical or surgical illness was recorded. Other causes of acne, hirsutism and alopecia were excluded by appropriate history and examination. All subjects underwent a detailed clinical examination with special reference to the following parameters: Hirsutism scoring was done using modified Ferriman-Gallwey (mFG score) and it was classified as mild (mFG score 9 - 16), moderate (mFG score 17 - 25) and severe (mFG score 26 - 36). Acne was graded as done by Indian authors using a simple grading system, which classifies acne vulgaris into four grades. Androgenic alopecia was looked for and graded as per Sinclair scale. It was also further classified as Ludwig type, Norwood Hamilton type and Olsen type. Acanthosis nigricans was looked for at multiple sites as neck, axilla, submammary area, intermammary areas, groins, elbows, knees, knuckles, dorsum of feet, cubital and popliteal fossa, periumbilical area, face-lips and eyelids. Other causes of the above symptoms and signs were excluded. Entire skin, hair, nails and mucosae were examined for any abnormality. Genitals were checked for any clitoromegaly or vulvar acanthosis. Galactorrhoea and thyroid fullness was looked for.

\section{RESULTS}

The peak incidence of polycystic ovarian disease was seen in patients with age group of 21 - 25 years followed by 26 - 30 years. Among the dermatologic and gynaecological complaints, hirsutism, i.e. a cutaneous manifestation was the most common, seen in upto $84 \%$ of the women and showed varying severity. The mean Ferriman-Gallwey score was $16.8+/-5.39$. Hirsutism was most commonly found over the upper lip and lower abdomen followed by thighs, upper abdomen and lower back, chest and upper back, chin and upper arms. Acne was seen in $70 \%$ of the patients. Grade II severity acne was the most common presentation followed by Grades III, I and IV respectively. The most common site was face followed by neck, back, upper arms and front of chest. Androgenic alopecia was seen in $32 \%$ of the women. The most common clinical type was Ludwig followed by Olsen and Norwood Hamilton type. As per Sinclair scale, grade II severity androgenic alopecia was most common. Acanthosis nigricans was seen in $56 \%$ of the patients. The most common site was nape of the neck followed by axilla, groin and submammary areas. The SAHA syndrome, i.e. the combination of seborrhoea, acne, hirsutism and androgenic alopecia was seen in 3 patients. Acrochordons were seen in $32 \%$ and seborrhoea was found in 30\%. Common gynaecological complaints were oligomenorrhea [62\%] and amenorrhea [12\%]. Married women commonly presented with infertility [68\%]. Significant proportions of our patients had increased BMI and were overweight or obese. Many of them also had central obesity with increased waist circumference and waist-hip ratio. A family history of polycystic ovarian disease was observed in many of the women, either in the mother or siblings, indicating a genetic predisposition to polycystic ovarian disease. Though most of the patients did not have diabetes mellitus, hypertension or coronary artery disease at the time of presentation, many of them had a family history of the same, indicating a predisposition to metabolic syndrome. Among the biochemical assays, though total testosterone was raised in only $6 \%$, free testosterone was raised in $32 \%$, indicating decreased SHBG levels. LH:FSH ratio was raised in $18 \%$ and serum prolactin was high in $20 \%$ of the women. Ultrasonography detected polycystic ovaries in $96 \%$ of the polycystic ovarian disease patients.

\section{CONCLUSION}

Polycystic ovarian disease is the most common chronic debilitating endocrinopathy of women in the reproductive age group with long-term health consequences. Dermatological problems like hirsutism, acne, androgenic alopecia, acanthosis nigricans and seborrhoea may serve as markers for identifying the polycystic ovarian disease syndrome, which may otherwise be resistant to routine treatments. Further studies are required to assess the grading of severity of these symptoms in PCOS patients, which may help to establish the severity of the syndrome. Also, these may serve as markers for patients at risk of developing metabolic syndrome. Early recognition of this disorder gives a chance to reverse the symptoms and signs associated with the disease, while correcting the metabolic abnormalities that may pose a significant health risk for untreated individuals and improving the physical, social and mental well-being of the patient. Early recognition also provides a chance for lifestyle modification [i.e. a comprehensive program of diet, exercise and behavioural therapy] that improves insulin resistance, dermatological complaints, menstrual 
irregularities, fertility and also decreases long-term health risks. However, more research in the genetic and environmental factors is needed to underscore preventive strategies in future in families with polycystic ovarian disease.

\section{KEY WORDS}

Polycystic Ovarian Disease, Acne, Hirsutism, Androgenic Alopecia.

HOW TO CITE THIS ARTICLE: Singh TR, Sudhamalla S. Cutaneous manifestations of polycystic ovarian disease. J. Evolution Med. Dent. Sci. 2018;7(26):3053-3057, DOI: 10.14260/jemds/2018/685

\section{BACKGROUND}

Polycystic ovarian disease (PCOD) is one of the commonest endocrine metabolic disorders affecting $6-10 \%$ of women in their reproductive age. ${ }^{1}$ Polycystic ovarian disease is characterised by anovulation and hyperandrogenism. Genetic predisposition coupled with lifestyle changes in the modern era play the key role to result in hyperinsulinaemia, polycystic ovarian disease and hyperandrogenism. ${ }^{2}$ In PCOD, basic defect is androgen excess and ovary is the primary site for androgen production. ${ }^{3}$ Polycystic ovarian disease is the most common endocrine cause of hirsutism, acne and androgenic alopecia. ${ }^{4}$ Since an initial report in 1980, progress in characterising the relationship between insulin resistance and polycystic ovarian disease has been substantial. ${ }^{5}$ Women with polycystic ovarian disease are both insulin resistant and hyperinsulinaemic in relation to weight matched controls. ${ }^{6}$ Insulin resistance is defined as reduced glucose response to a given amount of insulin, ${ }^{7}$ while chronic hyperinsulinaemia represents a compensatory response to target tissue problem. ${ }^{8}$ Insulin resistance is implicated in the pathophysiology of polycystic ovarian disease leading to hyperandrogenism and anovulation. ${ }^{9}$ Insulin resistance has genetic predisposition with complex heritage. Mechanism is mainly post-receptor failure.10 Insulin resistance is responsible for gynaecological and dermatological symptoms as well as metabolic manifestations like hypertension, dyslipidaemia, obesity and type II diabetes mellitus. ${ }^{11}$ Treatment of polycystic ovarian disease varies widely according to symptoms. ${ }^{12}$ South Asian women with polycystic ovarian disease are more likely to suffer from insulin resistance compared to Caucasians and have lower sex hormone binding globulin [SHBG] levels. ${ }^{13}$ It is important to recognise girls and young women at risk for polycystic ovarian disease, as early intervention may prevent long-term sequelae and improve quality of life. ${ }^{14}$

\section{Objective of Study}

To study the incidence of cutaneous manifestations like hirsutism, acne vulgaris, androgenic alopecia, acanthosis nigricans and other dermatological disorders in patients with PCOD.

\section{MATERIALS AND METHODS}

\section{Study Centre}

This study was undertaken in the Department of Dermatology, Venereology and Leprosy at Gandhi Hospital, Secunderabad.

'Financial or Other Competing Interest': None.

Submission 07-05-2018, Peer Review 10-06-2018,

Acceptance 16-06-2018, Published 25-06-2018.

Corresponding Author:

Dr. Thakur Rajeev Singh,

17-1-391/S/581,

Singareni Colony, Sayeedabad,

Hyderabad-500059, Telangana, India.

E-mail: rajeevtp@yahoo.com

DOI: $10.14260 /$ jemds $/ 2018 / 685$

\section{Study Period}

This study was conducted from December 2014 to June 2016.

\section{Sample Size}

Fifty cases of polycystic ovarian disease.

\section{Inclusion Criteria}

Patients in reproductive age group, both married and unmarried, who were diagnosed to have polycystic ovarian disease.

\section{Exclusion Criteria}

Patients with the following conditions are excluded from our study-

- Hypothyroidism.

- Prolactinoma.

- Cushing's syndrome.

- Congenital adrenal hyperplasia.

- Adrenal tumours.

- Hypothalamic amenorrhoea.

- Premature ovarian failure.

- Pregnant women.

\section{Methods}

This is a descriptive study. Informed oral consent was obtained from all subjects after explanation of the nature and purpose of the study. A detailed history regarding menstrual irregularities, reproductive function, hirsutism, acne, androgenic alopecia, acanthosis nigricans, acrochordons, seborrhoea and other skin changes. Patients were also enquired about use of cosmetics, hoarseness of voice, headache, milky discharge from breast, mass over anterior neck, weight gain, diet, exercise, use of any medications or other forms of treatment, any stress/ illness, history of diabetes mellitus, hypertension and coronary artery disease. Family history of polycystic ovarian disease, diabetes mellitus, hypertension, coronary artery disease, metabolic syndrome and cancers was also taken. Menstrual and obstetric history and any medical or surgical illness was recorded. Other causes of acne, hirsutism and alopecia were excluded by appropriate history and examination.

\section{Vitals}

(Pulse, blood pressure, temperature, respiratory rate) were recorded.

\section{Routine Investigations}

Included complete blood picture, complete urine examination, erythrocyte sedimentation rate, blood urea, serum creatinine and serum bilirubin.

\section{Biochemical and Hormonal Assays}

Included oral GTT, total and free testosterone, LH, FSH, TSH and prolactin. 


\section{Ultrasonography}

Done to diagnose polycystic ovaries.

\section{RESULTS}

The study was carried from December 2014 to June 2016 The study was carried out on patients who were diagnosed as polycystic ovarian disease. A total of 50 polycystic ovarian disease cases were studied.

\begin{tabular}{|c|c|c|}
\hline Age Distribution & Number of Patients & Percentage \\
\hline $15-20$ & 12 & $24 \%$ \\
\hline $21-25$ & 18 & $36 \%$ \\
\hline $26-30$ & 17 & $34 \%$ \\
\hline $31-35$ & 2 & $4 \%$ \\
\hline $36-40$ & 1 & $2 \%$ \\
\hline \multicolumn{2}{|c|}{ Table 1. Age distribution of Patients } \\
\hline
\end{tabular}

Secondary 9

$22 \%$

\section{Dermatological Manifestations}

\begin{tabular}{|c|c|c|}
\hline & No. of Patients & Percentage \\
\hline Nil or $\leq 7$ & 8 & $16 \%$ \\
\hline $8-16$ [mild] & 23 & $46 \%$ \\
\hline $\begin{array}{c}17-25 \\
\text { [moderate] }\end{array}$ & 14 & $28 \%$ \\
\hline$\geq 26$ [severe] & 5 & $10 \%$ \\
\hline \multicolumn{2}{|c|}{ Table 2. Hirsutism Score } \\
\hline
\end{tabular}

\begin{tabular}{|c|c|c|}
\hline & No. of Patients & Percentage \\
\hline Normal & 15 & $30 \%$ \\
\hline Acne & 35 & $70 \%$ \\
\hline \multicolumn{2}{|c|}{ Table 3. Prevalence of Acne Vulgaris in PCOD } \\
\hline
\end{tabular}

\begin{tabular}{|c|c|c|}
\hline & No. of Patients & Percentage \\
\hline Present & 16 & $32 \%$ \\
\hline Absent & 34 & $68 \%$ \\
\hline Table 4. Prevalence of Androgenic Alopecia in PCOD \\
\hline
\end{tabular}

\begin{tabular}{|c|c|c|}
\hline & No. of Patients & Percentage \\
\hline Present & 28 & $56 \%$ \\
\hline Absent & 22 & $44 \%$ \\
\hline Table 5. Prevalence of Acanthosis Nigricans in PCOD \\
\hline
\end{tabular}

\begin{tabular}{|c|c|c|}
\hline & No. of Patients & Percentage \\
\hline SAHA syndrome & 3 & $6 \%$ \\
\hline Acrochordons & 16 & $32 \%$ \\
\hline Seborrhoea & 15 & $30 \%$ \\
\hline Pityriasis capitis & 17 & $34 \%$ \\
\hline Telogen effluvium & 12 & $24 \%$ \\
\hline \multicolumn{2}{|c|}{ Table 6. Other Dermatological Findings } \\
\hline
\end{tabular}

\begin{tabular}{|c|c|c|}
\hline & No. of Patients & Percentage \\
\hline None & 29 & $58 \%$ \\
\hline Sibling & 12 & $24 \%$ \\
\hline Maternal & 9 & $18 \%$ \\
\hline \multicolumn{2}{|c|}{ Table 7. Family History of PCOD } \\
\hline
\end{tabular}

\begin{tabular}{|c|c|c|}
\hline Condition & No. of Patients & Percentage \\
\hline $\begin{array}{c}\text { Impaired glucose } \\
\text { tolerance }\end{array}$ & 5 & $10 \%$ \\
\hline Diabetes & 0 & $0 \%$ \\
\hline Hypertension & 2 & $4 \%$ \\
\hline Coronary artery disease & 0 & $0 \%$ \\
\hline Cancers & 0 & $0 \%$ \\
\hline
\end{tabular}

Biochemical Abnormalities

\begin{tabular}{|c|c|c|}
\hline & $\begin{array}{c}\text { No. of Patients showing } \\
\text { Elevated Levels }\end{array}$ & Percentage \\
\hline $\begin{array}{c}\text { Free } \\
\text { testosterone }\end{array}$ & 16 & $32 \%$ \\
\hline $\begin{array}{c}\text { Total } \\
\text { testosterone }\end{array}$ & 3 & $6 \%$ \\
\hline Table 9. Elevated Levels of Testosterone in Patients \\
\hline
\end{tabular}

Table 9. Elevated Levels of Testosterone in Patients

\begin{tabular}{|c|c|c|}
\hline & No. of Patients & Percentage \\
\hline$\geq 3$ & 9 & $18 \%$ \\
\hline$<3$ & 41 & $82 \%$ \\
\hline \multicolumn{3}{|c|}{ Table 10. LH/FSH Ratio } \\
\hline & No. of Patients & Percentage \\
\hline$\geq 24$ & 10 & $20 \%$ \\
\hline$<24$ & 40 & $80 \%$ \\
\hline \multicolumn{3}{|c|}{ Table 11. Serum Prolactin $(\mathrm{ng} / \mathrm{mL})$} \\
\hline
\end{tabular}

\begin{tabular}{|c|c|c|}
\hline & No. of Patients & Percentage \\
\hline Present & 48 & $96 \%$ \\
\hline Absent & 2 & $4 \%$ \\
\hline \multicolumn{2}{|c|}{ Table 12. Ultrasound Features of PCOD } \\
\hline
\end{tabular}

\section{DISCUSSION}

Polycystic ovarian disease is the most common reproductive disorder in women of child bearing age and has a prevalence of 6 to $10 \%{ }^{1}$ There are ethnic and racial differences in clinical and biochemical features of polycystic ovarian disease. $^{2}$

Hirsutism was noted in $84 \%$ cases in our study. Overall, the presence of hirsutism is a strong indicator of androgen excess (e.g. polycystic ovarian disease) with over $85 \%$ of hirsute women demonstrating some form of hyperandrogenism. ${ }^{11}$

In our study, the mean hirsutism score calculated using the modified Ferriman-Gallwey score was $16.81+/-5.39$. This is comparable and slightly higher than other studies by Espinos et al and Panadis et al,15,16 wherein the mean scoring of the hirsutism in the patients with polycystic ovarian disease was $12.0+/-4.4$ and $8.2+/-4.6$. In our study, acne vulgaris was present in $70 \%$ of the patients. This was comparable with Balen et al and Rosenfield's study who reported an incidence of acne as $66.2 \%$ and $70 \%$ respectively.6,17 Our value was slightly higher than the studies by Sivayoganathan et al and Ozdemir $\mathrm{S}$ et al, wherein both these studies showed the prevalence of acne to be $53 \%$ among polycystic ovarian disease patients. 18,19

Most of the patients in our study had grade 2 acne [54\%] followed by grade 3 [20\%], grade 1 [17\%] and grade 4 [8.57\%]. Polycystic ovarian disease is an important contributing factor in females with resistant acne vulgaris. $^{20}$ Androgenic alopecia was present in $32 \%$ of the 
cases in our study. This lies in between the prevalence values of Sivayoganathan et al (16\%), Kala K et al (17\%) and Ozdemir S et al (34.8\%).5,18,19

In the study by Cela $\mathrm{E}$ et al $67 \%$ of women with androgenic alopecia had polycystic ovarian disease, while only $27 \%$ women among the control group had polycystic ovarian disease. They also reported that the prevalence of polycystic ovarian disease was significantly higher in women with alopecia than in the control population. ${ }^{21}$

Acanthosis nigricans was found in $56 \%$ in our study with predominance in the neck region. This was higher compared to other studies done by Sivayoganathan et al $(23 \%)$ and Ozdemir S et al (5.2\%). ${ }^{18,19}$ Hud et al reported a prevalence of acanthosis nigricans in adult obese patients has been estimated to be $74 \%$.

Seborrhea was present in $30 \%$ of the cases. This is similar to the findings in Ozdemir $\mathrm{S}$ et al who found seborrhea in $34.8 \%$ of the polycystic ovarian disease patients. ${ }^{19}$

Acrochordons were noted in 32\% of the patients in our study. As per Kala K et al, acrochordons were noted in $16 \%$ of the patients. ${ }^{5}$

SAHA syndrome is characterised by the tetrad: seborrhea, acne, hirsutism and androgenic alopecia. In our study, the SAHA syndrome was seen in $6 \%$ of the patients. In contrast in the study done by Dalamaga et al, it was reported to be found in $17 \%$ of the patients. 22

In our study, $42 \%$ had family history of polycystic ovarian disease in mother or siblings. Based on the clustering of cases in families, polycystic ovarian disease is considered to be a heritable disorder. ${ }^{23,24}$

Impaired glucose tolerance was found in $10 \%$ of the women in our study. This finding is slightly lower than the study by Carmina E, wherein it was observed that the prevalence of altered glucose tolerance ranges between 20 and $35 \%$ in young women with polycystic ovary syndrome and this predisposes the patients to an increased risk for type II diabetes and cardiovascular diseases later in life. ${ }^{25}$

Moving from the young fertile age to the menopausal age, the prevalence of type II diabetes continues to increase and may reach $10-16 \%$ of polycystic ovarian disease women. ${ }^{8}$

Our study had shown $4 \%$ incidence of hypertension in study subjects, which signifies early onset of metabolic syndrome in polycystic ovarian disease group. ${ }^{26}$

In our study, $32 \%$ of study population had increased free testosterone levels. This signifies decreased SHBG levels, which can be considered as a surrogate marker of insulin resistance. Livadas $\mathrm{S}$ et al in their study reported elevated free testosterone in $17.2 \%$ of the patients with polycystic ovarian disease. ${ }^{27}$

About $20 \%$ of study subjects had $\mathrm{LH} / \mathrm{FSH} \geq 3$. An increase in LH pulse frequency explains this increase in the LH/FSH ratio. 28

In our study $20 \%$ of our study population had raised serum prolactin levels, which is comparable to other studies. $^{29}$ Patients with polycystic ovarian disease, administration of bromocriptine has reduced LH levels and restored ovulatory function. ${ }^{30}$

\section{CONCLUSION}

Dermatological problems like hirsutism, acne, androgenic alopecia, acanthosis nigricans and seborrhoea may serve as markers for identifying the polycystic ovarian diseases.
However, more research in genetic and environmental factors is needed to underscore preventive strategies in future in families with polycystic ovarian disease.

\section{REFERENCES}

[1] Hart R, Hickey M, Franks S. Definitions, prevalence and symptoms of polycystic ovaries and polycystic ovarian syndrome. Best Practice and Research Clinical Obstet and Gynaecol 2004;18(5):671-83.

[2] Wijeyarathne $\mathrm{CN}$, Balen $\mathrm{AH}, \mathrm{Barth} \mathrm{JH}$, et at. Clinical manifestations and Insulin Resistance (IR) among South Asians and Caucasians: Is there a difference? Clin Endocrinol (Oxf) 2002;57(3):343-50.

[3] Mehta J, Kamdar V, Dumesic D. Phenotypic expression of polycystic ovary syndrome in South Asian women. Obstet Gynecol Surv 2013;68(3):228-34.

[4] Palep-Singh M, Picton HM, Vrotsou K, et al. South Asian women with polycystic ovary syndrome exhibit greater sensitivity to gonadotropin stimulation with reduced fertilization and ongoing pregnancy rates than their Caucasian counterparts. Eur J Obstet Gynecol Reprod Biol 2007;134(2):202-7.

[5] Kala K, Datti SN, Sujatha C, et al. A study of clinical manifestations of polycystic ovarian disease among obese and non- obese rural women. Ind J of Basic \& Applied Med Research 2013;2(8):946-51.

[6] Balen AH, Conway GS, Kaltas G, et al. Polycystic ovary syndrome: the spectrum of disorder in 1741 patients. Hum Reprod 1995;10(8):2107-11.

[7] Goldzieher JW. Polycystic ovarian disease. Fertil Steril 1981;35:371- 94.

[8] Kopera D, Wehr E, Barbara Obermayer-Pietsch B. Endocrinology of Hirsutism. Int $\mathrm{J}$ Trichology 2010;2(1):30-5.

[9] Lowenstein EJ. Diagnosis and management of the dermatologic manifestations of the polycystic ovary syndrome. Dermatol Ther 2006;19(4):210-23.

[10] Azziz R, Ehrmann D, Legro RS, et al. Troglitazone improves ovulation and hirsutism in the polycystic ovary syndrome: a multicenter, double blind, placebo-controlled trial. J Clin Endocrinol Metab 2001;86(4):1626-32.

[11] Yildiz BO, Bolour S, Woods K, et al. Visually scoring hirsutism. Hum Reprod Update 2010;16(1):51-64.

[12] Rosenfield RL, Deplewski D. Role of androgens in the developmental biology of the pilosebaceous unit. Am J Med 1995;98(Suppl 1A):80S-8S.

[13] Futterweit W. Polycystic ovary syndrome: a common reproductive and metabolic disorder necessitating early recognition and treatment. Prim Care: Clinics in Office Pract 2007;34(4):761-89.

[14] Azziz R, Sanchez LA, Knochenhauer ES, et al. Androgen excess in women: experience with over 1000 consecutive patients. J Clin Endocrinol Metab 2004;89(2):453-62.

[15] Espinos JJ, Calaf J, Estadella J, et al. Hirsutism scoring in polycystic ovary syndrome: concordance between clinicians' and patients' self-scoring. Fertil Steril 2010;94(7):2815-6. 
[16] Panidis D, Tziomalos K, Papadakis E, et al. The clinical significance and primary determinants of hirsutism in patients with polycystic ovarian syndrome. European Journal of Endocrinology 2013;168(6):871-7.

[17] Rosenfield RL. What every physician should know about polycystic ovary syndrome. Dermatol Ther 2008;21(5):354-61.

[18] Sivayoganathan D, Maruthini D, Glanville JM, et al. Full investigation of patients with polycystic ovary syndrome (polycystic ovarian disease) presenting to four different clinical specialties reveals significant differences and undiagnosed morbidity. Hum Fertil (Camb) 2011;14(4):261-5.

[19] Ozdemir S, Ozdemir M, Gorkemli H, et al. Specific dermatologic features of the polycystic ovary syndrome and its association with biochemical markers of the metabolic syndrome and hyperandrogenism. Acta Obstet Gynecol Scand 2010;89(2):199-204.

[20] Maluki AH. The frequency of polycystic ovarian disease in females with resistant acne vulgaris. Journal of Cosmetic Dermatology 2010;9(2):142-8.

[21] Cela E, Robertson C, Rush K, et al. Prevalence of polycystic ovaries in women with androgenic alopecia. European Journal of Endocrinology 2003;149(5):439-42.

[22] Dalamaga M, Papadavid E, Basios G, et al. Ovarian SAHA syndrome is associated with a more insulinresistant profile and represents an independent risk factor for glucose abnormalities in women with polycystic ovary syndrome: a prospective controlled study. J Am Acad Dermatol 2013;69(6):922-30.
[23] Franks S, Gharani N, Waterworth D, et al. The genetic basis of polycystic ovary syndrome. Hum Reprod 1997;12(12):2641-8.

[24] Legro RS, Driscoll D, Straus JF III, et al. Evidence for a genetic basis for hyperandrogenemia in polycystic ovary syndrome. Proc Natl Acad Sci USA. 1998;95(25):14956-60.

[25] Carmina E. Polycystic ovary syndrome: metabolic consequences and long-term management. Scand J Clin Lab Invest Suppl 2014;244:23-6; discussion 26.

[26] Dokras A, Bochner M, Hollinrake E, et al. Screening women with polycystic ovarian disease for metabolic syndrome. Obstet Gynecol 2005;106(1):131-7.

[27] Livadas S, Pappas C, Karachalios A, et al. Prevalence and impact of hyperandrogenemia in 1, 218 women with polycystic ovary syndrome. Endocrine. 2014;47(2):631-8.

[28] Huang I, Gibson M, Peterson CM. Endocrine disorders. In: Berek JS, edr. Berek and Novak's Gynecology. 14th edn. Philadelphia, PA: Lippincott Williams and Wilkins 2007.

[29] Hall JE, Whitcomb RW, Rivier JE, et al. Differential regulation of LH, FSH and free alpha sub-unit secretion from the gonadotrope by gonadotropinreleasing hormone $(\mathrm{GnRH})$ : evidence from the use of two GnRH antagonists. J Clin Endocr Metabol 1990;70(2):328-35.

[30] Daan NM, Louwers YV, Koster MP, et al. Cardiovascular and metabolic profiles amongst different polycystic ovary syndrome phenotypes: Who is really at risk? Fertil Steril 2014;102(5):144451.e3. 